\title{
A Uniform Temperature Bathtub Model
}

\author{
liying Liu ${ }^{1, a}$ \\ ${ }^{1}$ School of Electrical and Electric Engineering, North China Electric Power University, Beijing, \\ 102206, China \\ aliuliyingjiu@sina.com
}

Keywords: Thermostatic Bathtub, Hot-Water-Supply-Drain, Energy Conservation Law

\begin{abstract}
Nowadays, with the improvement of people's living standard and the development of social science and technology, a considerable number of households equipped with a bathtub apparatus. Bathtub can clean and relax the body simultaneously. It is also a good way to makebloodcirculationmore smoothly, promotetheelimination of toxins and relieve stress.

But there is a problem for family bathtub. Unlike fountain or spa-style tub, it is just a simple water containment vessel. Consequently, the bath gets significantly cooler especially when the temperature is relatively low. Therefore thermostatic bath is particularly important. There are variousthermostaticbathon the market, and it has been more and more popular. Typically, however, a separate heating means more power and more expensive and remove traditional bath is not an easy task. So adding a constant trickle of hot water from the faucet to reheat the bathing water is a practical method. When the tub reaches its capacity, excess water escapes through an overflow drain.

This article intends to develop a mathematical model for the Hot-Water-Supply-Drain bathtub. We build Uniform Temperature Bathtub Model with the energy conservation law. We work out an equation based on several thermodynamics formulas. By analyzing the equation, we reach a conclusion that the most water-efficient method is to keep the tap water $45^{\circ} \mathrm{C}$ and the bathtub water $38^{\circ} \mathrm{C}$, in which state the tap water flow is $2.748 \mathrm{~L} / \mathrm{min}$.
\end{abstract}

\section{Uniform Temperature Bathtub Model}

In order to obtain the most fundamental simplified model, we create a Uniform Temperature Bathtub Model based on the heat conservation. That is to say, after the tap water trickling into the tub, the water in the bathtub immediately reaches a uniform temperature. Considering the tap water's heat is equal to heat the water surface lost and heat overflowed water taken away, the water surface losing heat includes the evaporator heat, the convection heat and the radiant heat. The specific calculation is as follows:

$$
\begin{gathered}
Q_{1}=Q_{2}+Q_{3}+Q_{4}+Q_{5} \\
Q_{1}=c m\left(U_{1}-U_{2}\right) \\
Q_{2}=c m\left(U_{1}-U_{2}\right) \\
m=Q \Delta t \\
Q_{3}=K_{1}\left(U_{2}-U_{1}\right) S \Delta t \\
Q_{4}=\beta\left(P^{\prime \prime}-P^{\prime}\right) S \Delta t
\end{gathered}
$$




$$
Q_{5}=\varepsilon \sigma\left(U_{2}+273\right)^{4} S \Delta t
$$

According to equations above, we get that:

$$
\begin{gathered}
U_{2}=\left\{\left[K_{1}+\beta\left(P^{\prime \prime}-P^{\prime}\right)\right] S U_{3}+c Q U_{1}\right\} /\left\{\left[K_{1}+\beta\left(P^{\prime \prime}-P^{\prime}\right)\right] S+c Q\right\} \\
Q_{1} \text { : The heat of faucet's water. } \\
Q_{2}: \text { The heat of water overflowed. } \\
Q_{3} \text { : Convective heat. } \\
Q_{4} \text { : Evaporation heat. } \\
Q_{5} \text { : Radiant heat. } \\
U_{1}: \text { Temperature of faucet's water. } \\
U_{2}: \text { Temperature of water in bathtub. } \\
U_{3}: \text { Temperature of the room air, } 20^{\circ} \mathrm{C} . \\
P^{\prime \prime}: \text { Vapor pressure of saturated water layer. } \\
P^{\prime}: \text { Vapor pressure of air. } \\
\varepsilon: \text { Blackness, } 0.97 . \\
\sigma: \text { Constant, } 5.6 \times 10^{-8} \text {. }
\end{gathered}
$$

Taking the data into above equation, we get that:

$$
U_{2}=\left(1496+4.2 \times 10^{3} Q U_{1}\right) /\left(74.8+4.2 \times 10^{3} Q\right)
$$

According to above equations, we get a picture showing the relation between $U_{1}$ and $U_{2}$ :

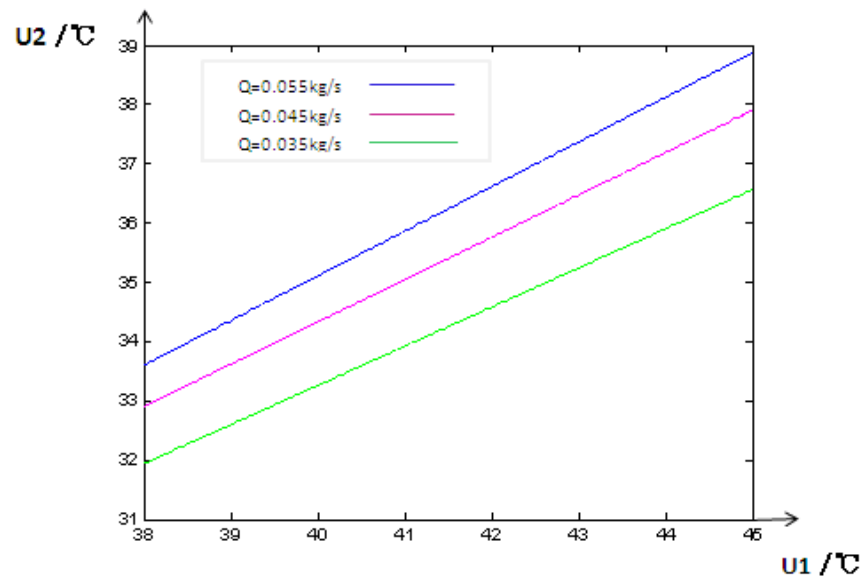

Figure 1 tub water temperature U2 vs. hot water temperature U1

We know that when people bath, the temperature shouldn't be higher than $45^{\circ} \mathrm{C}$, besides, we get that the higher $U_{1}$ is, the smaller $\mathrm{Q}$ is from the picture above. At the same time we know our aim 
is to get the smallest $\mathrm{Q}$ when it is possible. Taking the several points into consideration, we make a picture to show the relation between $\mathrm{Q}$ and $U_{2}$ assuming that $U_{1}$ is $45^{\circ} \mathrm{C}$.

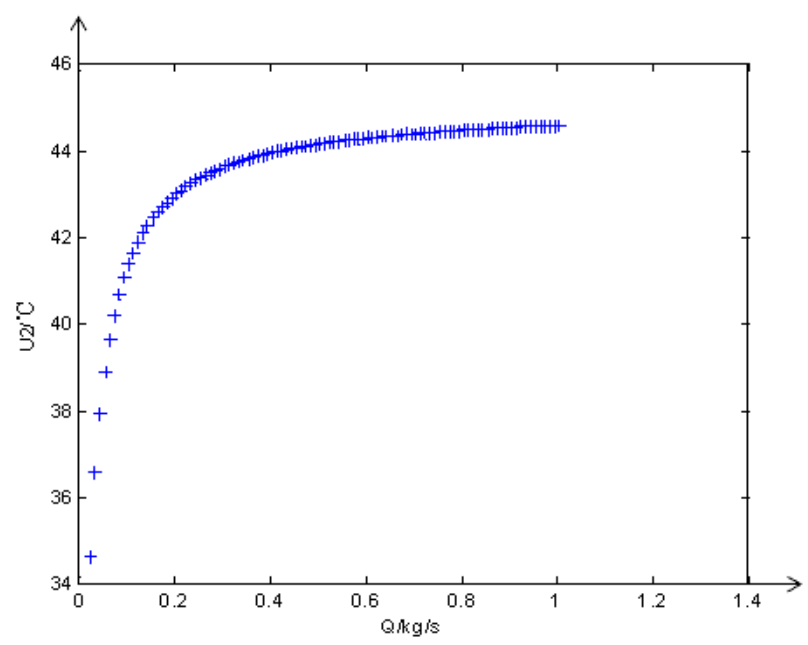

Figure 2 tub water temperature U2 vs. water flow Q

We already know that the most comfortable temperature for people to bath is $2{ }^{\circ} \mathrm{C}$ higher than people's body temperature, which is about $38^{\circ} \mathrm{C}$.

From the picture above we can see that to make the water comfortable for people to bath, the smallest Q is about $0.046 \mathrm{~kg} / \mathrm{s}$. The specific value we calculate out is $0.0458 \mathrm{~kg} / \mathrm{s}(2.748 \mathrm{~L} / \mathrm{min})$.

So we can reach a conclusion that the most suitable for people to bath and at the same time the most saving water method is to keep $U_{1} 45^{\circ} \mathrm{C}$ and $U_{2} 38^{\circ} \mathrm{C}$, in which state Q is $0.0458 \mathrm{~kg} / \mathrm{s}$ (2.748 $\mathrm{L} / \mathrm{min})$.

To make matters more intuitive, we have also produced a three-dimensional image as follows:
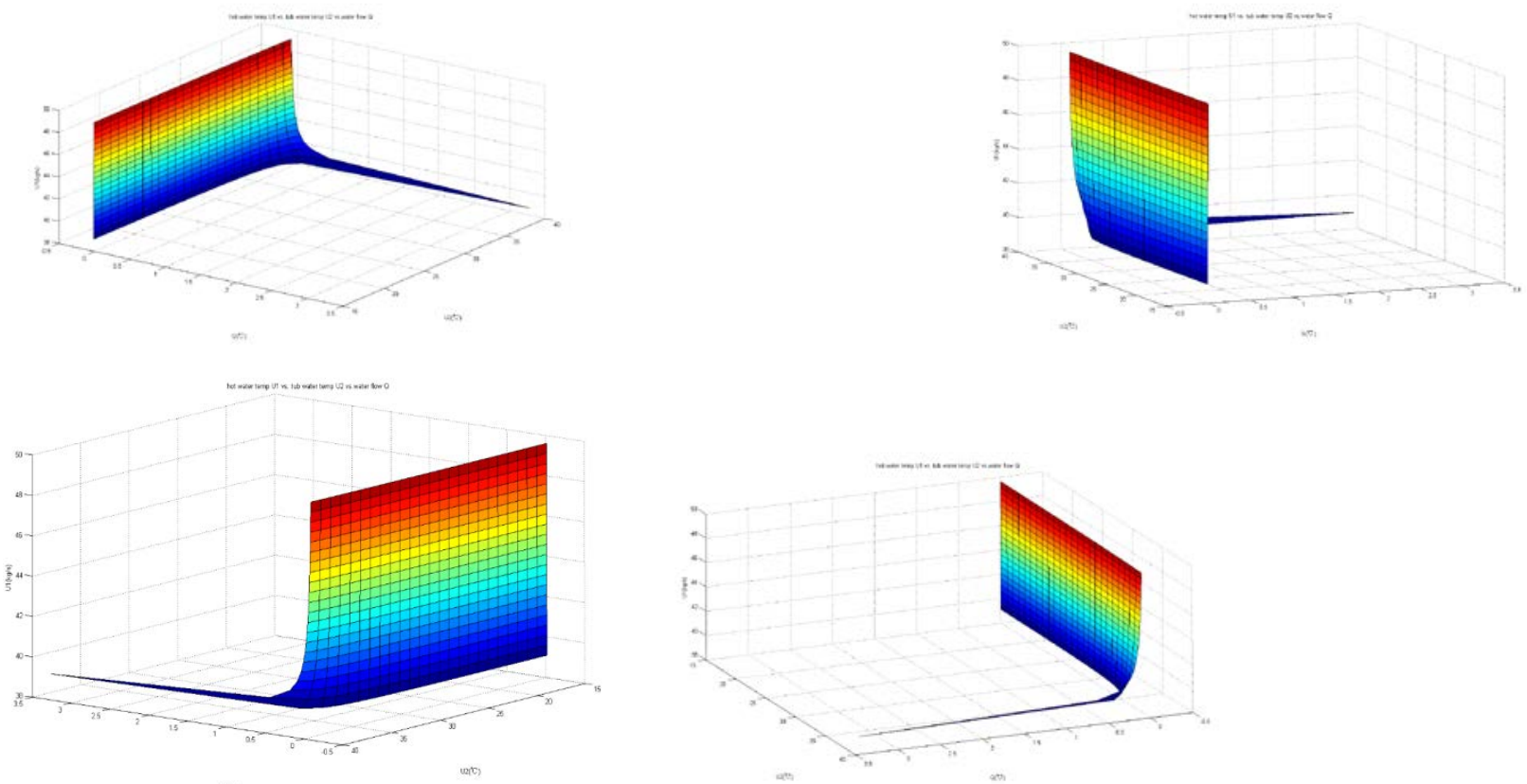

Figure 3 hot water temp U1 vs. tub water temp U2 vs. water flow Q 


\section{Conclusion}

According to the model we set, we reach a conclusion that the most water-efficient method is to keep the tap water $45^{\circ} \mathrm{C}$ and the bathtub water $38^{\circ} \mathrm{C}$, in which state the tap water flow is $2.748 \mathrm{~L} / \mathrm{min}$. With all these requirements satisfied, we can enjoy the bath healthily and the water could approximately keep an even temperature.

\section{Reference}

[1] Vivek V Ranade. Computational flow modeling for chemical react or engineering [M]. San Diego : Academic Press, 2002: 67-67.

[2] Marcel, NoraisUzel, Bernard Neveu, et al. Sludge filtration device comprising a filter piston and sludge filtration processthereof: US, 006110388A [P].2000-08-29.

[3]ChenHuiquan, Mao Shimin. Verification of universal formula of water vapor evaporation coeffici ent,1995.6

\section{通讯信息:}

\section{联系人高长青电话 13391797087}

地址: 山东省滨州市无棣小泊头镇南高村（顺丰、中通、申通）

邮编: 251900 